\title{
Developing outcome measures for the assessment of quality and competence of firms involved in legal aid work
}

This paper reviews research work already carried out and reported in eight papers presented to the Legal Aid Board by the authors between March 1996 and February 1997. These papers considered the efficacy of developing outcome measures assessment for firms involved in legal aid work, by looking at each principal subject area in detail, and in overview at both advice and assistance and litigation work. The recommendations of individual reports are brought together here, and a set of options for implementation are developed. Such options have become more focused in view of the Middleton Report and the policy changes announced by the Lord Chancellor. Pages 1-7 provide an overview and pages 7-24 give more detail on individual subject areas.

\section{Background}

Outcome measures are the fourth element of competence to be addressed under the preferred supplier system of legal aid franchising. Inputs and structure, as the first measures of competence are monitored under the Practice Management Standards which are part of the Specification for Legal Aid Franchising. The process of the work is assessed under a detailed system of "Transaction Criteria" written for each subject area of franchising and detailing basic information which would be expected to be found on the file of a competent practitioner working in each subject area. Looking at the outcomes of cases was "the final piece in the jigsaw".

The outcomes of legal cases are to be assessed in terms of:

- the length of time the case took to be resolved from beginning to end;

- the cost of carrying out the work and disbursements on the case;

- the results of the work carried out on the case;

- and the satisfaction of clients with the legal work carried out for them.

Some of these items are not value free or value neutral. Delay in handling a case might be detrimental to a client in relation to some issues but might be considered a benefit, or a good result in other cases, such as immigration cases, crime or public law children cases. Outcome Measures are therefore sometimes difficult to value. One element might be balanced against another, such as cost against results and client satisfaction against cost. There may also be societal results not immediately reflected in the legal result, such as a landlord making habitable a large number of buildings after a successful test case in relation to one.

The difficulties relating to outcome measures has been mentioned in "Lawyers:- The Quality Agenda" published by HMSO in 1994. In Chapter 2, we stated: 
"In relation to measuring competence it is clear again that there are no easy answers. Competence is such a multi-faceted concept that any successful attempt to measure it will need to combine a multiplicity of outcome, process and structural measures. The performance indicators which are used in the medical world... appear to have their parallels in certain output measures in the legal world. However, the transferability of such measures may be more apparent than real....Success rates on their own can be quite misleading."

\section{The statistical nature of outcomes measurement}

Global figures for Outcome Measures such as cost, delay and results, which all exist to some extent for England and Wales and for Legal Aid areas, are quite beguiling. It is possible to see clear differences in totals, in averages, in cases per head of population and in the range of the data for each area. The problems that exist in outcomes measurement are not reflected at these levels. There are clearly sufficient cases at this level to even out the individuality and randomness of the nature of legal cases.

It is at the firm level that the problems exist. Few firms have sufficient cases on which to operate a reliable comparison, either numerical or statistical. In order to make the appropriate comparisons it is essential to have cases which are similar. The Legal Aid Board's statistics clearly show that the numbers of similar cases concentrated within individual firms are very small. There is some possibility to compare (say) four or five firms across the country in some areas of work. However, the regional and other differences between such firms would make even this form of comparison unreliable.

The objective must then be to find, so far as is possible, the sources of variability between cases in order to bring as many cases into the line of similarity as possible. A major part of the research papers on outcome measures already delivered addresses exactly these issues. What are the variables which need to be understood and counted, which make sufficient difference to each case to bring it outside of the parameters of similarity with other cognate cases?

The results of this area of research, so far, are to be found in the individual research reports. However, one overall problem may be noted. It is still not possible, on a statistical basis, to decide what are the most appropriate variables in many areas of legal work because the basic information and data is in itself uncollected or unreliable. The problem here lies in the methods used for categorising legal cases. Traditional methods are based on the start of a case. However, cases develop and often change as they continue. The initial categorisation is rarely corrected. When such categorisations and data were only used for the purpose of stating overall figures this was not a problem. Now that more exact categories need to be defined and stated for the purpose of Outcome Measures, the categorisation issue becomes essential. Not only is there the problem of development within each case, but different areas, different solicitors and different staff all appear to have different approaches to categorisation of particular cases. The system needs careful revision before it can be used reliably. All 
of this is suggested in the individual papers; and much of it will have some effect on the way in which data is collected, categorised and reviewed by the Board's computer system.

Many items of data are still not properly collected. Results and result codes also remain uncertain in many areas of law. These need to be brought up to a common standard, in order to signify what might be important for Outcome Measures. The specific items have been mentioned in the individual subject reports.

Unfortunately, at the firm level, it is simply not possible to "sample" cases. The variability and range of cases is such that sampling methods with such small numbers of the total population of cases would not be valid. Within other areas of quality and competence monitoring in legal aid franchising it has been possible to sample files. This is because one can expect that practice management standards will be evident from all files and one can also expect that the appropriate individual sets of Transaction Criteria should be found on all files. But the same argument simply cannot apply to outcome measures. Even in relation to client satisfaction it is suggested that some areas of law (such as family law or immigration) must show a very different level of satisfaction from others.

Consequently, the current state of existing statistical data is such that it is not yet possible to tell with any certainty what variables are going to be important in understanding how outcome measures will work. Neither, therefore, is it possible at present to predict how strong or useful outcome measures will be in each subject area since the data does not exist on which such assumptions can be adequately tested. Although there is a variety of outcome measures research reported in the literature, none of these reports show a sufficiently robust, or inexpensive, system which could adequately be repeated across the country. So, although it must logically be correct that outcome measures will be useful and important in determining the competence of firms, the exact practical importance of such measures in situ remains to be tested properly.

\section{The options available}

Some decisions therefore need to be made on how to take these issues further. Options include:

\section{Wait and see - watch the pilot}

The research team has not stood still since conducting the outcomes research laid out in the initial papers. The ideas expressed in those papers have proved invaluable in designing and processing a system of categorisation both of cases and results to be used within the advice and assistance contracting pilot. The system designed by the researchers is known as "Briefcase" and contains all of the information upon which a categorisation system can be built. The first option therefore is to wait and see how the profession reacts to Briefcase and also to see what the results of Briefcase shows. 
It would then be possible to incorporate similar categorisation systems, relating to both cases and outcomes, into litigation cases and develop the remainder of the system from the bottom up.

This would have the advantage of bringing in a new system slowly, learning from mistakes at the advice and assistance level and building on experience, professional expertise and professional acceptability. It would also mean, probably, that such changes would keep pace with the likely changes to occur in the Legal Aid Board's new holistic computerised system. During the currency of the outcomes project, it was made clear that the changes which might be necessary in order to produce usable outcome measures could not immediately be accommodated on the Legal Aid Board computer in the first round. Allowing some time for such development would allow the development of outcome measures to go hand in hand with the development of the Legal Aid Board's computer system.

2. Work with existing data as quality triggers and develop incrementally Under this option it would be possible to use whatever data currently exists in whatever form it exists. At the same time this data could slowly be developed on the basis suggested in the different outcome papers already submitted. Under this option the Board would use such data as a part of a set of quality triggers, in order to monitor the work of firms involved in franchising and subsequently in contracting.

It will be seen from the individual reports that data does exist. The problem with this data is that it is either partial or unreliable. Because of the element of balance between different types of outcome measurement - such as complexity and cost, or damages and cost; it is quite difficult to assess the value of outcome measures in a vacuum without the corresponding balancing item also having been assessed. In addition, individual measures are themselves unreliable because of the categorisation difficulties mentioned above.

However, it might be thought useful to begin the process of outcomes measurement with existing data because that would enable more information to be built up regarding the acceptability of outcomes measurement. Reactions from the solicitors concerned would also be helpful in understanding the validity of the data and the importance of different variables. Such information could be used as "soft triggers" rather than hard triggers. In other words the information could be obtained, firms could be aware of this and discussions could be initiated when firms operated outside the triggered limits. But this need not lead to any contractual effect between the Board and the solicitors concerned.

By involving outcome measures at this stage the political difficulty of initiation of such a system would be overcome gradually and there would be more time to work out what they mean. The down side of using such information in any meaningful way would be the possibility that the entire process could be undermined because of the lack of any face validity for the current data. 


\section{Develop and accrue data for subsequent use}

This option is similar to Option 2 above, except that the outcome measures obtained would not be put into practice as part of a quality assessment system until their validity could be properly demonstrated. Under this option outcome measures would be developed over a period of time and consultation with the profession could well be a part of such development. A more careful approach to development would involve an holistic assessment of the relative balances between different elements of outcome measures so that if, and when, they are to be used this will be under careful conditions backed up by reliable and fully tested data.

The advantages of this approach are similarly that the data can be built up slowly over a period, to fit in with the needs of development of the new Board computer system. But, in this case the data can be carefully tested before it is let loose on solicitors, by which time it will be much more exact and more reliable and therefore be easier to "sell" as a quality measure.

The disadvantage of this, compared to Option 2, is that resources will be expended on the collection of data for some time before such data will actually be used. This might be difficult, especially if it involves solicitors in recording more information, without obvious return.

\section{Where should we start?}

Options 2 and 3 are clearly alternatives, but Option 1 could be combined with either of the other two options so that a "bottom up" and "top down" process could proceed at the same time. This would be the preferred option of the research team. It would mean that progress could be made both through advice and assistance upwards and through gradual change to litigation data from the top down.

Whichever route is taken, if outcome measures are to be considered as a mode of quality assessment, there will be some priorities to be set about which subject areas to follow through first. Decisions on how to prioritise the work should take into account the practicalities of development of outcome measures in particular subject areas, including especially areas with large numbers of cases and with considerable cost to the Legal Aid Fund, and should also take account of the views of other players in the field including the LCD, the Law Society, consumers associations etc. The Middleton Report and the Lord Chancellor's speech at the Law Society Conference suggest major changes in legal aid which will clearly be crucial to such decisions.

The process should involve a careful reading of this overview report and also of the initial reports in order to see exactly what needs to be done in each subject area. A summary of all these included later in this paper.

A preliminary trawl through the subject areas provides a hotchpotch of suggestions and difficulties: 
- Crime - this has problems because there seems to be little political will to carry out the work requested on the CREST system, as expressed in the recent letter from the Lord Chancellor's Department. Perhaps with more political effort it would be possible to re-examine this issue. Even if we were to go down the route of a public defender system as is being piloted in Scotland, it would still probably be necessary to look at outcomes of cases between different areas and different CPS regions. Outcomes of cases would be useful from the point of view of analysing CPS competence, the competence of defence lawyers, the use of courtrooms and the court service and much more. Information from some magistrates courts was due to be computerised well over ten years ago. It is not clear how the system can be sensibly organised without such information being available. It would be quite useful if the Crime Contracting Pilot could already begin a sensible system for noting assessing outcome measures. The researchers on that pilot have been made aware of our paper on outcome measures relating to crime, but there has been no recent contact on how outcomes measurement might be involved

- Matrimonial is the area which needs most attention on reclassification. It is here that so many cases start off under one heading and end up under another heading or should end up under many headings. The first stage here would be an enquiry into a sensible reclassification system. Suggestions have already been made in the paper on matrimonial work as to how this might look, but it is yet to be sent out to consultation with the professions. The work that Sarah Maclean is already carrying out at the Legal Aid Board must also clearly be taken into account. It would be useful for those carrying out the Family Mediation Pilot also to be aware of the need for sensible classification in relation to outcome measures which could be taken across into family work more generally. Once again, there has been little contact with the researchers working on that project. In that case I am not sure that our original family and children work has been shown to them. We would value such contact which may well be essential for the development of outcome measures in this expensive and difficult area of work.

- Personal Injury and Medical Negligence would have been a good area because our initial work shows some very interesting differences in approach between northern and southern regions, yet a similar balance between costs of cases and damages awarded. It might be thought sensible to wait for Pascoe Pleasence to conclude his own work in this area before launching further forays into it. There are also complications regarding conditional fees, fast track and it now appears that personal injuries may be removed from the Legal Aid Scheme altogether, although the position of medical negligence may not be so clear.

- Advice and assistance work will in general be carried forward under the contracting pilot and with the new Briefcase system. This is one area that can happily be left alone to proceed of its own accord.

- Housing work suggests a more selective approach in terms of outcome measures development. The issues are not simple and a brief exposition details these later in this paper. 
- Contract etc. proved to be a considerably understudied area which needs further development research in terms of initial profiling. This would involve some detailed work both at Legal Aid area offices and in some solicitors' offices looking at files. It could well be taken forward by the current research team, if considered to be among the initial priorities. Apparently legal aid may only be available in this area for defendants. It is still not clear what this will mean as the constituents of this subject area are so poorly understood

- Employment, welfare, immigration and debt also all have specific issues which are a little different in each case. Decisions as to which areas should be dealt with in priority among these are for further discussion. Some of these may also disappear from the legal aid agenda.

It will be seen that some areas have been placed "on hold" because other work needs to proceed outside of the research before we can go any further. One or two areas, such as "contract" cases need further research from us before they could be taken further.

In order to understand the detail within each subject area, the next section of this paper summarises issues which have arisen in the individual texts. It then proceeds to make some comments and suggestions for taking forward one, as yet under worked area of outcome measurement, client satisfaction.

The following parts of the paper were both written pre-Middleton. Rather than rewriting them in a short time frame, it is hoped that the reader will bear this in mind.

\section{Detailed Conclusions of the work so far}

This section of the paper brings together some of the main findings that have implications for the reform of legal aid, findings relating to the volume of work in individual firms and suggestions regarding client satisfaction.

\section{Categorising the legal aid scheme}

Categorisation is essential to any programme of reform. Given that legal aid is often conceived of in response to abstract principles (access to justice) and covers a vast array of potential problems, the task is not easy.

In practice, much of our work during the last year has been taken up with categorising. This has often raised central questions about how the scheme should be viewed.

Legal aid may be best thought of as three linked but essentially separate schemes, dealing with crime, family and other civil work. Of these, crime is the most expensive in terms of net expenditure, consuming around $£ 616 \mathrm{~m}$ in $1995 / 6$. By contrast, the family scheme cost around $£ 374 \mathrm{~m}$ net while the other civil scheme cost around $£ 402 \mathrm{~m}$. 
Below we look at each in turn.

\section{Crime}

Criminal legal aid scheme in England and Wales is not run by any one organisation. Instead, responsibility is highly fragmented. Decisions over whether an individual should receive legal aid are made by the courts; the Legal Aid Board runs the duty schemes and pays magistrates' courts bills; Crown Courts and Central Taxing Teams approves Crown Court bills, and their cost falls directly on the Lord Chancellor's Department.

Policy-makers usually think of criminal legal aid in terms of different 'schemes' - such as the duty solicitor schemes, green form, magistrates' court legal aid and higher court legal aid. However, these schemes cut across individual cases, which often start under the police station scheme, proceed through the magistrates' court and end up in the Crown Court. In practice, the divisions between schemes are malleable: solicitors have considerable discretion over whether to conduct work under the green form scheme or under magistrates' court legal aid. They may also choose whether work should be conducted early (under magistrates' court legal aid) or later (under the Crown Court scheme).

This separation of responsibility between 'schemes' has implications for policy towards criminal legal aid:

- First, crime is rarely given the attention it deserves. Although it matters to many people a bit, it matters to no-one a lot.

- Secondly, reform tends to be piecemeal. Magistrates' court standard, for example, were introduced without considering their effect on green form expenditure.

- Thirdly, essential information cannot be co-ordinated. For example, applications data held by magistrates cannot be linked with bills paid by the Board; bills paid by the Board cannot be linked to bills on the same case paid by the Crown Courts. The lack of information is a serious impediment to quality monitoring.

In its 1996 White Paper, the former Conservative Government declared its intention to hand over greater responsibility to the Legal Aid Board. Whatever the merits of this proposal in the long term, it has caused further short-term difficulties. It has, for example, placed a question-mark over the future of the Central Taxing Teams and prevented any capital investment in their future. Thus they do not have a direct computer link to the COMSHARE database. Information is manually entered from photocopied forms, which reduces its accuracy.

An outstanding feature of English criminal legal aid is that it is top heavy. Crown Court legal aid consumes more money than magistrates' court legal aid. Within Crown Court expenditure, the top fifth of cases consume four-fifths of expenditure, while the top $1 \%$ of cases consume two-fifths of expenditure. The most expensive 300 or so cases represent less than half a percent of expenditure, but a third of net costs. The 
former Conservative Government proposed to deal with these high cost cases through a special budget. Its White Paper, however, did not indicate how important the high cost case budget would be. If one assumes that it would cover the most expensive $20 \%$ of Crown Court cases, it would consume almost half the total budget for criminal representation.

\section{Family}

Family work may be divided between divorce, ancillary and public law children's matters. It is a major net expenditure for the legal aid scheme and operates quite differently from Crime and Civil work. A detailed approach is taken in our paper on outcomes measurement as outlined above.

\section{Civil work}

Civil work used to be considerably less important than either family or crime. However, its costs have risen considerably over the last five years, and it has now overtaken family work in term of net cost.

Unlike crime and family work, which are allocated a single franchise category each, civil work boasts no less then seven separate franchise categories. However, these were developed in relation to the green form scheme, and they do not necessarily correspond to certificated work.

Table 1 shows net spend on certificated cases divided between the main heads of work, as categorised by the Board's computer. These differ from the franchise categories, and it is often difficult to convert the one to the other. In particular, it is unclear what the contract/consumer franchise covers, though it may include contract and 'other negligence' (which are mainly actions for professional negligence brought against accountants, lawyers etc.). On this basis, contract/consumer is the largest category accounting for $26 \%$ of the net budget, followed by personal injury (25\%) and housing (15\%). The social welfare areas (debt, welfare benefits, employment and immigration) cover bankruptcy, the employment appeal tribunal and much of judicial review - but account for only a tiny proportion of total spend (probably under 5\% between them).

It is worth noting that around a quarter of the budget is spent on areas that are not franchised, including 'general' tort, company/partnership disputes and probate. 
Table 1: Net cost of civil legal aid cases closed in 1995/6, by category of work

Personal injury

Net cost \% of budget

Contract

$£ 55.2 \mathrm{~m}$

25

Housing (Landlord and tenant

\& lands)

$£ 39.8 \mathrm{~m}$

18

$£ 33.9 \mathrm{~m}$

15

Children (adoption, wardship,

abduction etc.)

$£ 27.3 \mathrm{~m}$

12

Tort - general

$£ 23.5 \mathrm{~m}$

11

Other negligence (including legal)

$£ 17.6 \mathrm{~m} \quad 8$

Judicial Review

$£ 8.7 \mathrm{~m}$

4

Company and partnership claims

$£ 4.6 \mathrm{~m}$

2

Probate, Inheritance Act and Trusts

$£ 3.0 \mathrm{~m}$

1

Bankruptcy

Employment Appeal Tribunal

$£ 1.7 \mathrm{~m}$

1

$£ 0.5 \mathrm{~m}$

*

House of Lords and Court of Appeal

$£ 3.3 \mathrm{~m}$

1

Other

$£ 2.6 \mathrm{~m}$

1

Total

$£ 221.4 \mathrm{~m}$

100

Source: Legal Aid Board's database

An assumption behind legal aid policy has been that most 'other' civil work is either personal injury or housing work, or sufficiently like personal injury and housing work to be treated in the same way. Yet personal injury and housing between them account for only two-fifths of net expenditure. Before embarking on legal aid reform, there is an urgent need to find out more about the other major areas, including contract, other negligence and general tort. One also needs to consider how relatively rare areas will be treated, including judicial review, probate, company and partnership claims.

During the course of our work, we asked how much money is spent on businessrelated litigation. It is impossible to answer this question without further research. However, a rough guess suggests that it must be approaching $£ 20$ million net a year. There has been remarkably little discussion of the merits of legal aid as a way of meeting the legal needs of small businesses. Yet legal aid seems poorly adapted to the task: help is only provided when the income limits are reached, which (almost by definition) means that the business has already failed. Thought could be given to whether Government help might not be better directed through legal expenses insurance policies. 


\section{High-volume firms?}

Outcome measures, like other statistical quality measures, require a high volume of similar cases. Legal aid, however, remains an extremely general scheme. Work is handled by a mass of firms, each of which often conducts only a handful of cases in each area. Our research revealed time and time again just how few cases the average legal aid firm conducts.

One strand of thinking behind the former Conservative Government's White Paper was to concentrate legal aid among fewer firms, and to contract with them for reasonably high volumes of work. Examples of contracts tended to talk in terms of hundreds of cases per year. It was said that this would build on the existing franchising scheme. It is true that when franchising was first considered, it had been intended to confine franchises to high-volume firms. After protest from the Law Society, however, the volume requirements were abolished. The result is that many franchised firms conduct relatively small volumes of work. A move in which the Board contracted for hundreds of similar cases would involve a major redistribution of work, and would have serious implications for access to the scheme.

It is worth illustrating these points with a few examples. The Legal Aid Board changed its computer system in August 1995, which means that its green form figures are based on the eight months from August 1995-March 1996 rather than a year.

\section{Employment}

Relatively little green form employment work is carried out, but it is distributed among over 4,000 firms. The result is that most solicitors conducting work submit only a few bills. Only 24 firms submitted more than 25 bills (equivalent to 38 a year) and only three firms submit more than 50 (equivalent to 75). No firms undertook more than 100 cases. Given these low figures, it perhaps surprising that 456 firms have received employment franchises. The fact that a firm has an employment franchise does not mean it specialises in such work. Over half of all franchised firms submit under 15 green form bills per year.

Table 2: Concentration of employment green form bills among solicitors firms: proportion of account holders (AHs) paid for each band August 1995 - March 1996.

\begin{tabular}{ccc}
$\begin{array}{c}\text { No. of bills paid from } \\
\text { Aug 95 and March 96 }\end{array}$ & $\begin{array}{c}\text { \% of AHs in } \\
\text { each band }\end{array}$ & $\begin{array}{c}\text { Number of } \\
\text { AHs in each band }\end{array}$ \\
\hline $1-10$ & 95 & 4,148 \\
$11-25$ & 4 & 181 \\
$26-50$ & $*$ & 21 \\
$51-100$ & $*$ & 3 \\
All AHs with employment bills & 100 & 4,353
\end{tabular}




\section{Debt}

Over 6,000 firms conducted some debt cases, but the vast majority (94\%) handled less than the equivalent of 38 cases a year. Only 126 firms conducted over 75 cases a year. Yet 474 offices have a debt franchise.

Table 3: Concentration of debt green form bills among solicitors firms: proportion of account holders (AHs) paid for each band August 1995 - March 1996.

\begin{tabular}{ccc}
$\begin{array}{c}\text { No. of bills paid from } \\
\text { Aug 95 and March 96 }\end{array}$ & $\begin{array}{c}\text { \% of AHs in } \\
\text { each band }\end{array}$ & $\begin{array}{l}\text { Number of } \\
\text { AHs in each band }\end{array}$ \\
\hline $1-10$ & 78 & 5,089 \\
$11-25$ & 16 & 1,029 \\
$26-50$ & 4 & 262 \\
$51-100$ & 1 & 91 \\
$101-200$ & $*$ & 27 \\
$201-500$ & $*$ & 6 \\
Over 500 & $*$ & 2 \\
All AHs with debt bills & 100 & 6,506
\end{tabular}

\section{Housing}

The figures for green form housing work are very similar to those for debt and are not repeated here. However, it is interesting to consider the distribution of certificated housing work. Again, most firms operating in the field do only a few cases each year. As Table 4 shows, almost three-quarters do five cases or fewer, and 96\% do 25 cases or fewer. Only 59 firms could be described as bulk practitioners undertaking more than 100 cases each year. This is despite the fact that 514 firms now hold a housing franchise.

Table 4: Payments made under certificates for housing work 1995-96

\begin{tabular}{lrr} 
Number of cases & Number of accounts & $\%$ \\
\hline $1-5$ & 5,136 & 73 \\
$6-10$ & 1,060 & 15 \\
$11-25$ & 559 & 8 \\
$26-50$ & 155 & 2 \\
$51-100$ & 84 & 1 \\
$101-200$ & 37 & $*$ \\
$200+$ & 19 & $*$
\end{tabular}

Source: Legal Aid Board $\quad *=$ under $1 \%$.

It might be possible to work with these figures if all housing cases were similar. However, our consultation exercise showed that even specialist firms carry out a spread of work. It suggests that a typical profile for a firm handling over 200 housing cases might be as follows: 
Public housing repossessions

Repairs cases

Private repossessions

Mortgage repossessions

Illegal eviction/harassment

Homelessness

Long leaseholders' service charges
$50+$

$50+$

25-50

under 25

under 25

under 25

under 10

\section{Total}

$200+$

It is interesting to think through the implications these figures may have for a contracted scheme. They suggest that even if one contracted with only the very largest firms, one might be talking about, say, 18 illegal evictions or 6 service charge cases, producing an inflexible distribution of work. It may be better to think about contracting not for cases but for housing 'credits'. Thus if a public housing repossession was worth 1 credit, a private repossession might be worth 1.5 , while a judicial review was worth 5. Working out the credit system, however, will be a major undertaking (and will only be suitable for the largest firms).

The problems of contracting for low numbers may be eased by concentrating work among a few firms. However, this policy has serious ramifications both for access and for competition. Just to give an illustration, if one assumed that each firm would do an average of 150 housing litigation cases per year and the total number of cases remained at the 1994/5 rate, there would be only 126 housing firms in England and Wales, each serving an average population of 406,000. On this basis, even major cities such as Bristol (pop. 367,000) and Teesside (pop 363,000) would no longer be able to sustain their own firm of legal aid housing solicitors. Of course, this assumes that the budget is evenly distributed (which it is not: see below). If the present regional imbalances are preserved, some regions may have only two or three firms in all.

\section{Regional differences}

A major, but unacknowledged, feature of the present legal aid scheme is its regional differences. There are clear differences in the amount spent in each of the 13 legal aid regions, but these become more pronounced if one looks at how the money is spent. There are differences in the cost of claims, in the number of claims and in the type of claims.

\section{Differences in the cost of claims}

Table 5 highlights differences in gross cost. It shows that regional variations are large and consistent. Across all categories of case except "other" personal injury, gross costs in the most expensive area are more than double those in the cheapest area. For medical negligence, they are three times as high. 
Table 5: Gross costs of closed certificated legal aid cases: regional variations.

Personal injury figures are for cases closed 1994/5. Non-personal injury cases are for cases closed 1995/6

\begin{tabular}{|c|c|c|c|c|c|}
\hline & $\begin{array}{c}\text { National } \\
\text { mean }\end{array}$ & $\begin{array}{l}\text { Highest } \\
\text { region }\end{array}$ & $\begin{array}{c}\text { 2nd highes } \\
\text { region }\end{array}$ & $\begin{array}{l}\text { Lowest } \\
\text { region }\end{array}$ & $\begin{array}{c}\text { 2nd lowes } \\
\text { region }\end{array}$ \\
\hline PI: work & $£ 2,800$ & $\mathrm{~L}: £ 4,690$ & SW: $£ 4,416$ & $\mathrm{~N}: £ 1,473$ & Mye: $£ 2,062$ \\
\hline PI: road & $£ 3,257$ & SE: $£ 4,511$ & S: $£ 4,393$ & $\mathrm{~N}: £ 2,033$ & NW: $£ 2,511$ \\
\hline PI: med neg & $£ 4,038$ & $\mathrm{~L}: £ 7,442$ & S: $£ 4,678$ & SWls: $£ 2,448$ & Ch: $£ 2,461$ \\
\hline PI: other & $£ 1,800$ & $\mathrm{~L}: £ 2,654$ & SW: $£ 2,618$ & SWls: $£ 1,412$ & $\mathrm{~N}: £ 1,422$ \\
\hline $\begin{array}{l}\text { Contract (non } \\
\text { employment) }\end{array}$ & $£ 2,215$ & $\mathrm{~L}: £ 3,047$ & $S: £ 2,916$ & Mye: $£ 1,493$ & Ch: $£ 1,617$ \\
\hline $\begin{array}{l}\text { Professional } \\
\text { negligence }\end{array}$ & $£ 2,891$ & L: $£ 4,476$ & S: £4,104 & $\mathrm{N}: £ 1,969$ & Mye: $£ 2,060$ \\
\hline General tort & $£ 1,378$ & L: $£ 1,934$ & S: $£ 1,716$ & $\mathrm{~N}: £ 807$ & WM: £ 934 \\
\hline
\end{tabular}

Key to legal aid areas: Ch: Chester and North Wales, L: London, Mye: Merseyside, N: Northern, NW: North Western, S: Southern, SE: South Eastern, SW: South Western, SWls: South Wales, WM: West Midlands.

Source: Legal Aid Board's database of closed cases

In broad terms, there is a North/South divide. The South includes London, Southern, South Eastern and South Western. The North includes South Wales, West Midlands, Merseyside, North Eastern, North Western, Northern and Chester and North Wales.

The North/South divide is more important than the divide between London and the provinces. Although London usually has the highest costs, its figures are usually only just above those of the South Western, Southern or South Eastern areas. In road accident cases, costs in the South Eastern and Southern areas exceed those in London. Only for medical negligence cases are London costs significantly higher than those of the rest of Southern England.

\section{'Elite' and 'mass' areas}

Differences in gross cost are linked to other differences. Solicitors in the North take a 'mass' approach: they handle a large number of claims per head of population, but deal with each case relatively cheaply, and settle for small amounts of money. The South takes an élite approach. They take fewer claims per head of population, but each one costs more and receives more compensation. 
This can be seen from the following graph that examines accidents at work. It looks at the variation of each regional mean from the national mean (expressed as a percentage of the national mean). Thus, for example, the Northern area has a rate of claim that is $165 \%$ higher than the national mean, but gross costs that are $47 \%$ lower. The top four 'élite' areas have low rates of claims, but put substantial effort into litigating the cases they do take. In return, they receive high damages.

The bottom three areas take a 'mass' approach. They have high rates of claim and low times, costs and damages.

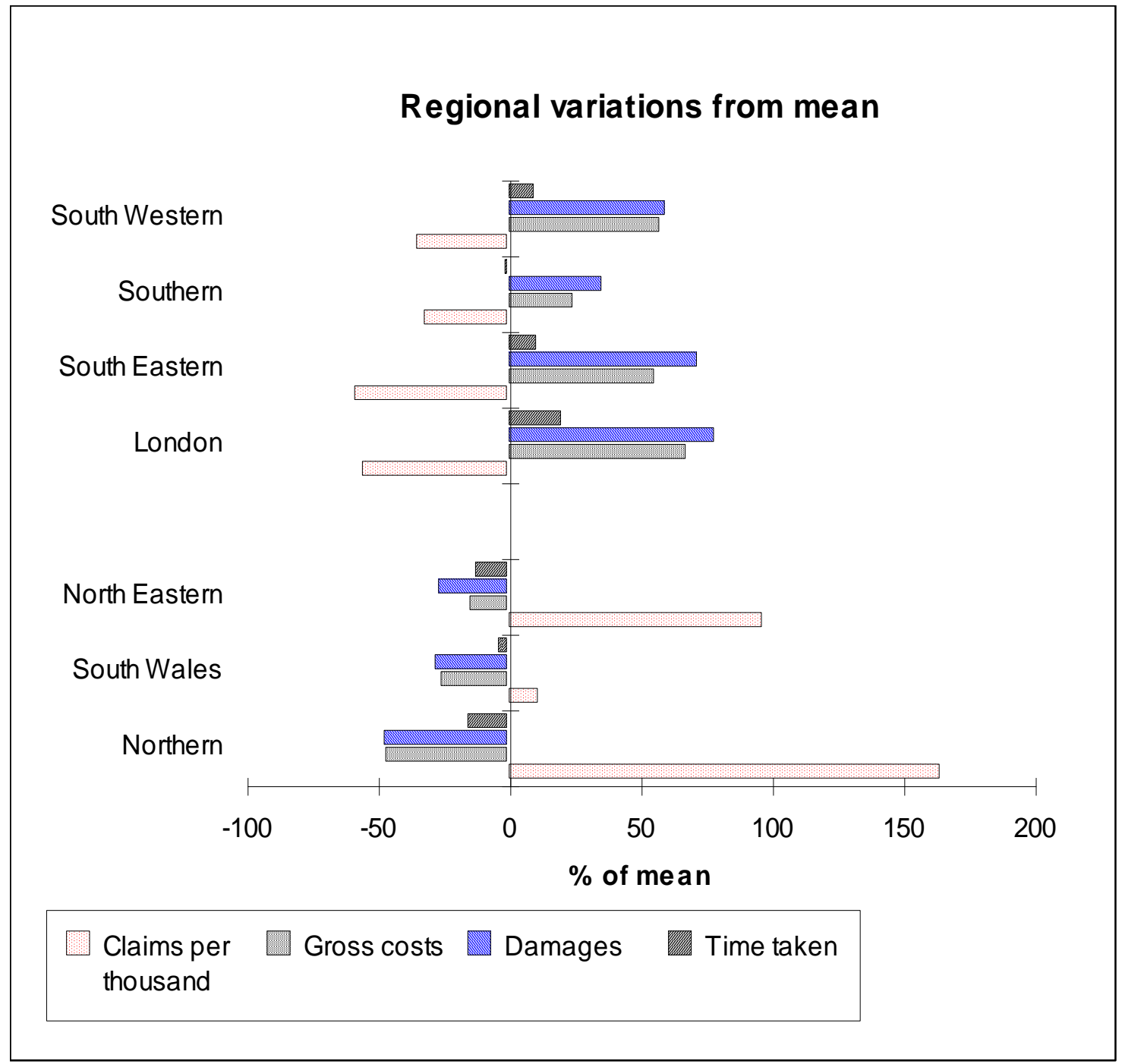

Source: Sherr et al 1996.

\section{Differences in the type of claims}

On top of these general differences in legal culture are other differences that relate to specific types of work. Social welfare law is particularly unevenly distributed between areas. For example, housing work is overwhelming concentrated in just three areas: Merseyside, West Midlands and London. These take half $(51 \%)$ of all housing green forms. For certificated repair cases, the claim rate per head of population is highest in Merseyside with 53 claims per 100,000 people. The equivalent rate for the West Midlands is 33 claims and for London 19 claims. The North Western area 
shows a claim rate of 18 and South Wales a rate of 11 . The other areas, however, all show rates of 5 or under.

These figures relate claims to population, not to a 'need index'. Work on welfare benefits, however, suggests that only a small proportion of regional differences can be accounted for by objective differences in 'needs'.

Table 6 shows regional differences in welfare benefits green form bills. The first column shows the number of welfare benefit bills submitted to each area office between August 1995 and March 1996. Column 2 shows the Legal Aid Board's 'need index' for each area. Column 3 multiplies the need index by the population, giving a population figure (in thousands) which is 'adjusted' to take account of needs. The final column shows the number of bills per 'adjusted' 10,000 population.

Table 6: Regional differences in number of green form bills submitted (August 1995 March 1996)

\begin{tabular}{lrccc} 
& $\begin{array}{c}\text { Bills } \\
\text { submitted }\end{array}$ & $\begin{array}{c}\text { LAB's need } \\
\text { index }\end{array}$ & $\begin{array}{c}\text { Need index } \\
\text { x pop (000s) }\end{array}$ & $\begin{array}{c}\text { Bills per 10,000 } \\
\text { 'adjusted' pop }\end{array}$ \\
\hline 1. London & 9,657 & 1.25 & 8,710 & 11 \\
2. South Eastern & 2,929 & 0.97 & 3,915 & 7 \\
3. Southern & 2,021 & 0.88 & 3,890 & 5 \\
4. South Western & 2,870 & 1.04 & 4,290 & 7 \\
5. South Wales & 1,756 & 1.27 & 2,795 & 6 \\
6. West Midland & 14,420 & 1.16 & 4,855 & 30 \\
7. North Western & 12,400 & 1.23 & 4,300 & 29 \\
8. Northern & 11,581 & 1.21 & 3,942 & 29 \\
9. North Eastern & 4,068 & 1.23 & 5,411 & 8 \\
10. East Midlands & 8,311 & 1.01 & 4,442 & 19 \\
11. Eastern & 2,240 & 0.91 & 4,753 & 5 \\
12 Chester \& N.Wales & 3,814 & 1.08 & 3,022 & 13 \\
15 Merseyside & 23,541 & 1.38 & 2,916 & 81 \\
All & 99,608 & 1.00 & 51,621 & 19
\end{tabular}

The final column shows that even when variations in need, have been taken into account there are significant differences in the take-up of welfare benefit green forms. While Merseyside submits 81 bills per adjusted 10,000 population, Southern and Eastern submit only 5. Redistributing provision based on needs would mean cutting welfare benefit advice in Merseyside to around a quarter of its present level. The service provided in the West Midlands, the North West and North would need to be reduced by about a third. This has policy ramifications which have yet to be thought through. 


\section{Summary}

The work on outcome measures has raised the following issues:

- The fragmentation of responsibility for criminal legal aid has serious implications for reform. Some of the basic information about the cost and outcome of cases is not available. This will make quality monitoring difficult.

- The English Crown Court legal aid scheme is top heavy. The Very High Cost Case budget will consume a high proportion of total expenditure.

- There is an urgent need to find out more about contract, other negligence and general tort claims funded under legal aid. In particular, legal aid's role in assisting small businesses should be discussed.

- The implications of reform for relatively rare areas of work (such as judicial review, probate and company work) need to be thought through.

- There is a need to consider the concentration of work entailed by contracting, and to model the implications such concentration would have for access and competition.

- Regional variations are large and multi-layered. Moving from the present system to one based on need will have major political ramifications. There are lessons to be learnt from health service policy, including the ill-fated Resource Allocation Working Party.

\section{Client Satisfaction and other areas of remaining research}

One priority in future work is client satisfaction. Nearly all the outcomes papers raise this as an issue, and promise further work on it.

In relation to client satisfaction, it is necessary to distinguish between two types of monitoring:

- asking clients questions they want to answer about the legal service provided to them; and

- asking clients questions about our conception of legal competence which only clients can answer.

Both types of questioning would be useful. The first would provide real consumer information and the second would provide a useful check on other areas of monitoring competence.

Initially a short 'think-piece' should be produced before moving on to both qualitative and quantitative pilots. The following issues need to be addressed: 
1. The greatest challenge lies in ensuring a sufficient response rate. The personal injury paper states that we should aim to achieve a response rate of at least $20 \%$. Response rates can be raised by providing:

- a short, clear questionnaire, with a reply-paid envelope and two reminders;

- a questionnaire that addresses clients' own concerns, in language which clients use;

- an appropriate incentive (we need to brain-storm on what that might be. A money payment for every returned questionnaire? A prize draw?)

To ensure that the questionnaire addresses clients' own concerns in their own language, one might start by conducting qualitative work with clients, either individually or in groups.

2. How far should each questionnaire be subject specific, and how far should different areas be addressed by the same questionnaire? Clearly, the more general the analysis, the fewer questionnaires one needs in each subject.

3. What is the minimum sample required per firm? How will the sample be chosen? When will questionnaires be sent out and by whom?

4. What questions will be asked, and how will they be analysed?

\section{A summary of previous recommendations for further research}

This section summarises the recommendations for further work in our Interim Reports on Outcome Measures. It starts by looking at the main areas of civil litigation including housing, personal injury and contract/consumer. It then discusses crime, advice, assistance and tribunal representation. All the recommendations about client satisfaction are brought together at the end.

The recommendations concerning family and child care law are more detailed and it is necessary to consider the original papers on these.

The final paragraph (in italics) summarises the present position.

\section{Personal Injury and Medical Negligence}

We recommended that at a conceptual level, personal injury claims were suitable for outcome measurement. However, there were practical problems in collecting data and in securing sufficient data.

The paper recommended further analysis of LAB's closed database and changes to CIS.

\section{Further analysis of LAB's closed file database}


By looking at the data already collected about some 100 or so individual firms, one could explore the following questions:

- What is the minimum number of cases a firm needs to do in each category of work before the results become meaningful?

- How does one cope with outliers - the very expensive, or successful, or lengthy cases - which distort mean figures?

- How does one deal with regional differences? In particular, are regional differences greater (or less) than differences between individual firms?

- Is it true that specialist firms have better cost to damages ratios than generalist firms? What would be the cost implications of moving work away from generalists to specialists?

We also suggested that in a few cases (say up to 20 firms), researchers would visit the firms to explore with them possible reasons for the differences in outcomes.

This information could also be gathered specifically for medical negligence cases.

\section{Changes in the way CIS collects information}

We recommended that the Board should record some new information, of which the most important were:

- clients' age and gender

- days spent in hospital

- the solicitor's assessment of the severity of injuries

- other information relating to the complexity of the case

We also recommended that work accidents should be distinguished from work-related conditions acquired over time and that the Board should provide guidance on what the new categories (such as pavement trips) include.

Work has been put on hold until LABRU has completed its own study Once the $L A B R U$ study is completed, we should reconsider whether to proceed with this work and especially in relation to medical negligence.

\section{Contract, Professional Negligence and General Tort}

Our paper argued that very little was known about these important areas. Before considering outcome measures, there needs to be a programme of basic research to find out more about the type of work done and its outcomes. It would address the following questions:

1. What type of work is presently funded?

2. What are the non-monetary benefits of such work (in terms, for example, of injunctions obtained and claims defeated)? 
3. What factors add to cost?

4. What factors increase or decrease chances of success?

5. Why are there regional variations in both number of claims and their success rate?

6. How far do London and other major centres draw work from other areas?

It recommended that work should proceed in four stages:

- A pilot classification has already been suggested for contract work, and a similar classification should be developed for non-personal injury negligence.

- A greater understanding of how the merits test is applied could be gained from asking staff in different offices to 'talk through' how they would deal with similar applications.

- Once classifications have been developed, it will become possible to use application forms to code cases. By recording the number of each case, information from the application form can be tied in with other information held on the Board's database on gross and net costs and on damages received.

- The application forms give an indication of other issues at stake, such as whether the assisted party was applying for an injunction or defending a claim. Unfortunately the Board's database does not record whether they succeeded. For a full analysis of the result of such actions, it would be necessary to go to solicitors' files. As there are no transaction criteria for these areas of work, extracting information from files cannot be done alongside transaction audits but would require additional work.

This work would be of use for a range of policy initiatives (including prioritisation, contracting and the merits test). It would also be useful in establishing baseline data for the Woolf reforms.

Even though legal aid may now only be available for defence of contract claims, this area may still need study.

\section{Crime}

Our paper pointed out the problems with applying case result measures to criminal work. Such a system would be complex and highly data intensive. It would be expensive to collect all the required data, and the system would have uncertain results.

It recommended that if the Board wished to proceed with case result measures, it should enter into negotiations with the Lord Chancellor's Department about the new CREST programme by the end of April 1997.

It appears that the Lord Chancellor's Department has decided not to include outcome measures within the CREST specification. In view of this, we need to find some other method to see how case result measures can be progressed in this area. 


\section{Housing litigation}

The housing paper looked separately at advice work, possession actions, repair cases and other work.

- Advice work is discussed separately below.

- Possession actions: only routine possession actions for rent arrears are suitable for outcome measures. At present, legal aid only regularly funds such actions in London. Elsewhere in the country, routine possession actions are not usually thought eligible for a legal aid certificate.

The paper concluded that if the Board decided to extend legal aid to routine possession actions (though duty schemes, for example), they could be monitored using outcome measures. However, unless and until such a decision is taken, little further work on possession outcomes can be undertaken.

- Repair cases: The paper identified three possible objectives in funding repair cases: to secure legal rights; to provide clients with homes that are in good repair; and to ensure that landlords carry out their legal duties to all their tenants. It argued that in order to proceed with outcome measures, one needed to set the objective.

The Board needs to consider its objectives in funding repairs work. Until a policy decision is taken on the objectives, no further research should be undertaken.

- Other cases: These include homelessness, illegal eviction and work for long leaseholders. The numbers involved are too small to be suitable for outcome measures. It recommended that new transaction criteria should be written for these cases.

Further work on housing litigation awaits a reconsideration of the new parameters for legal aid.

\section{Advice work}

In our 'think-piece', we concluded that it was very difficult to apply case result measures to pure advice work. This has, however, been overtaken by our work on the advice and assistance pilot (see above).

\section{Transaction criteria}


Given the importance of transaction criteria, we recommended that their operation should be reviewed. This clearly now appears to be happening. Both the employment and debt papers explored this further. The employment paper highlighted the following issues:

- Transaction criteria cover only a minority of potential problems. New criteria need to be written to cover other major areas of work.

- Care needs to be taken to ensure a sufficient sample of files.

- Transaction criteria can easily go out-of-date.

- At present, each question is rated equally. Yet some vital issues are covered in only a single question, while other less important issues may be covered in five or six. A system for checking systematic failures was recommended in the original Birmingham pilot but has not yet been introduced.

- Thought needs to be given to whether issues should be explored at a particular time.

- Careful guidance needs to be given about the appropriate level at which work should be pursued.

The debt paper noted that the existing transaction criteria recommend a 'money advice' technique. It recommended further investigation of how auditors reconcile such demanding standards with what solicitors can realistically do in a couple of hours.

We need to consider whether to monitor further how transaction criteria are working in practice.

\section{Other quality approaches}

It addition, we recommended exploring other quality measurement systems including:

- client satisfaction

- work product inspection, in which an expert in the field considers the written record of advice given. This has been used by NACAB to survey the quality of housing advice ${ }^{1}$ and employment advice. ${ }^{2}$

- model clients.

\footnotetext{
${ }^{1}$ D. Forbes and S. Wright, Housing Cases in Nine CABx, 1990.

2 See Legal Action April 1996.
} 
Client satisfaction is dealt with below. Model clients and peer review will be explored during the green form pilots. Further consideration should be give to work product inspection.

\section{Assistance}

Our 'think-piece' followed PSI in defining assistance as cases that involve 'communication with third parties, during which the client's case is put forward' - but that do not involve litigation or representation at tribunals.

Unlike pure advice work, assistance cases may lead to a tangible outcome that can be measured. The main problem, however, is that few 'level 3' cases are carried out. It is likely that individual firms carry out too few similar cases in any one area to even out the random element.

These problems were explored at length in both the immigration and debt papers. The debt paper concluded that if the Board were to decide to fund more in-depth money advice, it may be possible to include an element of outcome measurement within the pilot study. However, the paper stressed that outcome measures would require a sophisticated understanding of how results related to other factors, such as the client's income and household circumstances, the type of debts and local economic changes. Developing outcome measurements for money advice would need to be part of a broader research programme into money advice itself.

The welfare benefits paper concluded that social security assistance often led to tangible benefits for clients. However, almost $90 \%$ of firms carried out fewer than 25 green form cases - and their work was spread between 36 different benefits. There are unlikely to be sufficiently large volumes in any given area to apply outcome measures. That said, if it proved possible to group benefits together, one might consider outcome measures for the largest firms. The green form pilot will explore this in further detail.

Further work on outcome measures for advice work should await the results of the green form pilot.

\section{Tribunal representation}

The 'think-piece' found at a theoretical level tribunal representation could sensibly be measured through outcome measures. The employment paper discussed the issues involved in detail.

However, the Legal Aid Board cannot consider applying such measures unless and until it is decided to bring tribunal representation within the legal aid scheme.

No further work on tribunal representation can usefully be carried out until such a policy decision is taken. 


\section{Client satisfaction}

The papers all recommend that further work should be conducted on client satisfaction.

For example:

- The personal injury paper called client satisfaction 'an important additional measure'. The majority of solicitors consulted recommended that it should be included. However, the paper noted practical problems. These included the difficulty of securing a sufficient response rate; whether to send out separate questionnaires for personal injury work (or one general one for all civil work); and issues in defining the sample. It stated that we would return to these questions after considering other areas of work.

- The welfare benefits paper also found that most firms supported client satisfaction measures. However, there were particular problems in ensuring that welfare benefit clients returned their forms. One firm sending out its own questionnaires reported a response rate of only $15 \%$. Thought also needed to be given about when to send out questionnaires. Clients were most likely to respond while the case was live (i.e. before it had been completed). However, they may not have the full information on which to judge the service.

- The crime paper found that criminal solicitors were split on whether client satisfaction should be measured: two-fifths were in favour (often strongly in favour) and three-fifths were against (sometimes strongly against). The paper recommended that it should be measured but that 'solicitors are clearly right to point out that it will be difficult to persuade criminal clients to return questionnaires'. It promised that the issue would be considered in a separate paper.

Client satisfaction is an important outstanding issue. It is recommended that work on client satisfaction should be given some priority in any further work on outcome measures. 